Ser y hacer del servicio comunitario: aproximación desde el contexto formación inicial en Educación Especial

Yarines Perdomo ( Pp. 4-26)

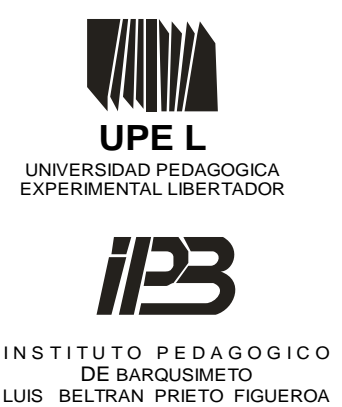

DE BARQUSIMETO
LUIS BELTRAN PRIETO FIGUEROA

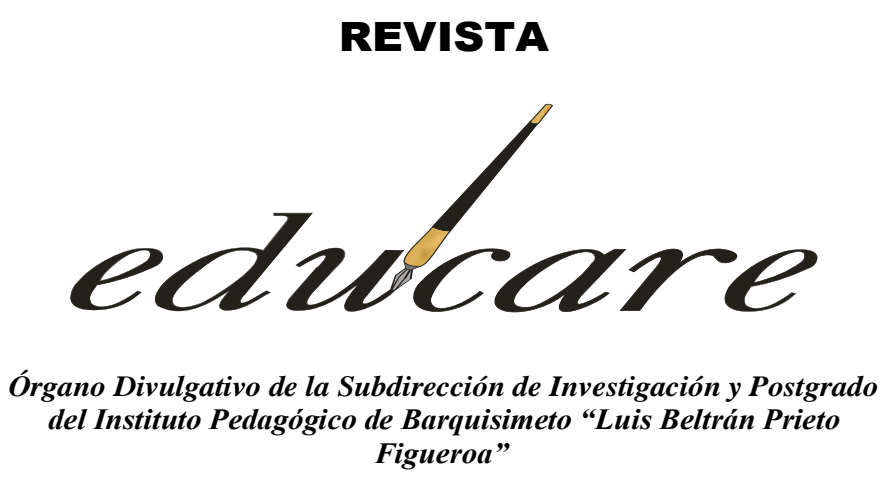

Figueroa"

BARQUISIMETO - EDO. LARA - VENEZUELA

NUEVA ETAPA

FORMATO ELECTRÒNICO

DEPOSITO LEGAL: ppi201002LA3674

Volumen 18 № 3

ISSN: 2244-7296

\title{
SER Y HACER DEL SERVICIO COMUNITARIO: APROXIMACIÓN DESDE EL CONTEXTO FORMACIÓN INICIAL EN EDUCACIÓN ESPECIAL
}

COMMUNITY SERVICE BEING AND DOING: APPROACH FROM

THE CONTEXT OF INITIAL FORMATION IN SPECIAL EDUCATION

\begin{abstract}
Yarines Perdomo*
* Universidad Pedagógica Experimental Libertador - Instituto Pedagógico de Barquisimeto (UPEL - IPB)
\end{abstract}


Ser y hacer del servicio comunitario: aproximación desde el contexto formación inicial en Educación Especial

Yarines Perdomo ( Pp. 4-26)

SER Y HACER DEL SERVICIO COMUNITARIO: APROXIMACIÓN DESDE EL CONTEXTO FORMACIÓN INICIAL EN EDUCACIÓN ESPECIAL

\section{COMMUNITY SERVICE BEING AND DOING: APPROACH FROM THE CONTEXT OF INITIAL FORMATION IN SPECIAL EDUCATION}

TRABAJO DE INVESTIGACIÓN

Recibido: 12-09-2014
Yarines Perdomo*

UPEL - IPB

Aceptado: 03-12-2014

\section{RESUMEN}

Las universidades enfrentan el reto de formar docentes capaces de transformar su praxis pedagógica, ello se configura como una exigencia social y una necesidad institucional. Este estudio tuvo como propósito generar una aproximación teórica sobre el ser y hacer del servicio comunitario de los docentes en formación inicial en educación especial; se subscribe en la metodología documental de desarrollo teórico: la revisión exhaustiva de sus referentes permitió construir un nuevo saber desde la dimensión epistemológica, ontológica, axiológica, gnoseológica y pedagógica. Se concluye que la perspectiva del ser sobre el hacer, depende primordialmente de las fortalezas personales, de las habilidades pedagógicas que se tengan para llevar a cabo una práctica reflexiva significativa y de la promoción del amor por lo que se hace, todo ello es la raíz que sustenta la formación inicial del docente en educación especial. Las experiencias exitosas del hoy, estimulan los cambios virtuosos y emancipadores del mañana.

Descriptores: Educación especial, servicio comunitario, el ser y hacer docente.

\begin{abstract}
Universities face the challenge of training teachers who are able to transform their pedagogical praxis, which is a social demand as well as an institutional need. The present study aimed to generate a theoretical approach about the teachers' community service being and doing in their initial training in special education. The research was framed within documental research methodology of theoretical development. Exhaustive revision of referents allowed building a new knowledge from the epistemological, ontological, axiological, gnoseological and pedagogical dimensions. It is concluded that the perspective of being over doing depends mainly on personal potential, pedagogical abilities to achieve a significant reflexive practice and the promotion of love for what people do; all of it is the root supporting the initial formation of the special education teacher. Today's successful experiences enhance significant liberating changes for tomorrow.
\end{abstract}

Keywords: special education, community service, teacher's being and doing.

\footnotetext{
* Profesora del Programa Educación Especial (UPEL-IPB), Magister en Educación Especial, Doctora en Ciencias de la Educación de la ULAC. Correo Electrónico: dra.yarinesperdomo@gmail.com
} 


\section{Ser y hacer del servicio comunitario: aproximación desde el contexto formación inicial en Educación Especial Yarines Perdomo ( Pp. 4-26)}

\section{INTRODUCCIÓN}

Los acelerados cambios de este siglo obligan a la universidad a plantearse una revisión interna, que le permita adecuar su proceso formativo de una manera efectiva y que responda a su propio contexto sociocultural y al sentir de sus propios actores como parte indispensable su ser y hacer (Peña, 2006).

Es así como en América Latina, diversos estudios realizados por distintas organizaciones, como la Organización de las Naciones Unidas para la Educación, la Ciencia y la Cultura (2008), señala en la Conferencia Internacional de Educación titulada la Educación Inclusiva, el Camino hacia el Futuro, el potencial que tiene el proceso formativo en la prefiguración de construir la nueva sociedad. De allí, el papel primordial de la educación universitaria, de forma que este impulso educativo fecunda la vivencia de procesos transformadores de la sociedad.

Desde esta perspectiva, en el informe final de la conferencia antes citada se destaca que en las últimas décadas la realidad de América Latina, ha estado caracterizada por la diversidad de factores y eventos que configuran el campo educativo, tanto para el uso del conocimiento como para el estudio y la formulación e implementación de soluciones que satisfagan las necesidades educativas; que a su vez contribuyan al desarrollo de la comunidad social para mejorar la calidad de la vida humana en colectivo.

En tal sentido, las universidades enfrentan el reto de formar docentes capaces de transformar su praxis pedagógica para atender con gran calidad humana a los niños, niñas y jóvenes en su proceso formativo. Esta visión, es el sustento requerido para abordar acciones que permitan optimizar la formación de un nuevo profesional, que responda a las exigencias humanas del contexto educativo actual y por consiguiente de la sociedad venezolana, quien exige la formación de docentes participativos con auténtico cambio personal y profesional.

Así pues, la calidad de la docencia universitaria se configura cada vez más como una exigencia social y una necesidad institucional, por lo que trata de mejorar su actuación formativa al asumir protagonismo en la formación de profesionales con suficientes 


\section{Ser y hacer del servicio comunitario: aproximación desde el contexto formación inicial en Educación Especial \\ Yarines Perdomo ( Pp. 4-26)}

competencias académicas y comprometidas con la transformación de la realidad en que actúan.

En este proceso, el documento final de la Organización de Estados Iberoamericanos para la Educación, la Ciencia y la Cultura (2010), titulado "2021 metas educativas la educación que queremos para la generación de los bicentenarios", destaca en los programas de acción compartido el papel de las universidades y de las instituciones responsables de la formación del profesorado, los cuales deben garantizar la calidad de sus procesos formativos mediante estrategias con indudables repercusiones positivas con el fin de que los futuros profesionales de la docencia puedan adquirir las competencias necesarias para el ejercicio de su trabajo profesional.

Desde lo señalado, cabe hacer énfasis en la Educación Especial, la cual constituye una de las modalidades del sistema educativo venezolano, que se enmarca dentro de los principios y fines de la educación general, tal como lo señala la Ley Orgánica de la Educación (2009), y sustentada legalmente en la Constitución de la República Bolivariana (1999) la educación que debe prestar atención a las personas con discapacidad para su incorporación y permanencia en el sistema educativo, desde una visión humanista social.

Se trata entonces, resaltar que la educación es un fundamento para desarrollar las destrezas emocionales en el educar, siendo ello el valor significante de la dimensión humana. Al educar no se puede dejar a un lado el componente emocional tanto del que enseña y del que aprende; solo y a través de la interacción con el otro es como se logra la autorrealización del ser. En tal sentido, el docente en formación inicial de educación especial, según Giménez (2007), debe demostrar su sensibilidad impregnada de un potencial creativo hacia el logro de acciones educativas desde una perspectiva humanística

y sobre todo con una actitud emocional positiva que genere optimismo, entusiasmo y compromiso social para cambiar y transformar la realidad.

De allí, se requiere cambios profundos en la Educación Universitaria, por lo que Maza (2001), señala que tales cambios deben corresponderse con los que se gestan en el país y en el mundo y que permita a las instituciones universitarias iniciar una nueva etapa, que se caracterice justamente por ser innovadora, creativa y constructiva. 


\section{Ser y hacer del servicio comunitario: aproximación desde el contexto formación inicial en Educación Especial \\ Yarines Perdomo ( Pp. 4-26)}

Así pues, carreras como la Educación Especial enfatizan en desarrollar en los futuros profesionales de la docencia una actitud reflexiva sobre el sentir y el actuar como elementos primordiales en su desarrollo profesional. Al respecto, Martínez (1997), enfatiza que el elemento cognitivo nunca puede ser disociado del elemento afectivo. Es importante destacar, que la Organización de las Naciones Unidas, para la Educación, la Ciencia y la Cultura (2009), en su Conferencia Mundial sobre la Educación Superior: La Nueva Dinámica de la Educación Superior y la búsqueda del Cambio Social y el Desarrollo, plantea la necesidad de formar a los estudiantes para que se conviertan en ciudadanos profundamente motivados, provistos de un sentido crítico y capaces de buscar soluciones, es decir, el futuro docente y sobre todo el de Educación Especial, debe formarse como un ser competente, responsable y comprometido con el desarrollo social de la modalidad, su comunidad y país en general.

En virtud a lo anterior, Pérez (2009), señala que la Universidad necesita integrarse más a la comunidad y colocar a los futuros docentes desde su formación inicial en contacto con la realidad por lo que le permite fortalecer la pertinencia social para dar respuesta a los grandes problemas educativos de oblación excluida y que ha desertado del sistema educativo formal, por tanto enfatiza en la experiencia de atención no convencional para desarrollar en dichos estudiantes las competencias que fortalezcan su perfil desde los escenarios comunitarios.

Visto así, ese futuro docente requiere formarse como activista y transformador de la realidad social, formación que se promueve mediante la prestación del Servicio Comunitario; que según la Ley del Servicio Comunitario del Estudiante de Educación Superior (2005), lo define como la actividad que desarrolla en las comunidades los estudiantes aplicando los conocimientos humanísticos y científicos adquiridos en su formación, en beneficio de la comunidad.

En la Universidad Pedagógica Experimental Libertador, (UPEL, 2011) el Documento Base del Currículo propenda el desarrollo de un modelo pedagógico innovador de calidad, reflejado en el desarrollo de competencias académicas, personales y sociales, que permitan al docente en formación inicial adaptarse y generar cambios en su contexto para responder 


\section{Ser y hacer del servicio comunitario: aproximación desde el contexto formación inicial en Educación Especial \\ Yarines Perdomo ( Pp. 4-26)}

a sus necesidades reales con una visión del ser que se relaciona de manera cónsona con los desafíos emergentes de una sociedad cambiante. Desde esta concepción, la formación inicial del estudiante universitario de educación especial curricularmente debe estar en consonancia con la propuesta curricular de su casa magna, que enfatiza en que la realidad debe ser conocida, interpretada, comprendida, valorada y transformada por la acción de los actores sociales quienes, tienen el compromiso de contribuir al desarrollo de la persona y proporcionar mayor calidad de vida a los ciudadanos que estarán bajo su responsabilidad.

En este sentido, el documento antes mencionado en su basamento filosófico destaca, que los fines de la formación del futuro docente están centrados en los procesos de desarrollo humano integral, que implica el fortalecimiento de las capacidades intelectuales, de la innovación y la transformación y el fomento de la creación de nuevos conocimientos para atender los problemas sociales; desde sus fundamentos psicológicos planteados bajo el enfoque socio histórico cultural resalta, que mediante el aprendizaje colaborativo el futuro docente podrá conocer diferentes perspectivas para abordar un determinado problema. De allí, que en su sustentación sociocultural la UPEL como institución de educación universitaria formadora de formadores, propone mediante su nueva acción curricular, que los estudiantes de formación inicial alcancen y ocupen un lugar protagónico en su contexto social para superar las crisis latentes en el ejercicio del ámbito educativo.

En los actuales momentos, se puede decir que desde la UPEL el Servicio Comunitario contribuye a desarrollar esas competencias en el futuro docente de activista social asumiendo el rol de servidor comunitario. De allí, que esta indagación documental de desarrollo teórico construye un nuevo saber del Ser y Hacer del Servicio Comunitario en el contexto de la formación inicial de estudiantes de educación especial, desde la dimensión epistemológica, ontológica, axiológica, gnoseológica y pedagógica. A continuación se presenta la construcción teórica emergida luego de una exhaustiva revisión y análisis de diversas posturas de autores como: Prieto (1978), Morin (2001), Pérez (2007), Seligman (2005), Roger (1978), Villarini (2006), Goleman (1997), Maturana (2011), entre otros. 


\section{DESARROLLO}

\section{Ser y Hacer del Servicio Comunitario en el Contexto de la Formación Inicial de Estudiantes en Educación Especial}

La aproximación teórica que a continuación se presenta, surge del análisis y criticidad de postulados en función de develar el compromiso y la ética para enfrentar exitosamente el trabajo social que implica el servicio comunitario, considerando las dimensiones de disponibilidad y accesibilidad para disminuir el obstáculo de discriminación social que viven las personas con discapacidad. Similarmente, se vislumbra como un aporte para fortalecer la Atención No Convencional desde la formación inicial del docente en Educación Especial, destacando que éste requiere educarse como ser social a partir de la interacción y contacto con la sociedad y a pesar que las prácticas profesionales no la abarcan en su totalidad el servicio comunitario es, un medio y un fin para alcanzarlo.

Con este planteamiento, la universidad cumple con la responsabilidad social que le corresponde con la comunidad, legitimándola como actora participativa frente a las necesidades reales de ésta, mediante la acción activa de los estudiantes en formación comprometidos con los problemas sociales que acontecen. Por tal razón, la formación de los futuros profesionales en el ámbito de la educación especial, requiere cambios cruciales y sustentables, por lo que hoy día no se requiere solamente de pedagogos llenos de conocimientos sino, de mentores de la enseñanza que alcancen la recursividad del ser, el saber, el sentir y el convivir en la búsqueda de optimizar la calidad de vida de sí mismo y el de la comunidad; en la voz del maestro Prieto (1978) "la educación no se refiere al hoy transitorio, sino que mira el porvenir" (p.24).

Las prácticas formativas en boga en universidades e institutos pedagógicos según lo destaca Pérez (2007), han descuidado lo primordial: "la construcción y fortaleza de la identidad del educador y el desarrollo pleno de su personalidad" (p.124); no se puede dejar a un lado que el docente aprende e interioriza la práctica que experimenta en su proceso de formación, por lo general enseña cómo le enseñaron a él.

Revista EDUCARE, Volumen 18, Número 3, Septiembre - Diciembre 2014. ISSN: 2244-7296 Página 10 


\section{Ser y hacer del servicio comunitario: aproximación desde el contexto formación inicial en Educación Especial \\ Yarines Perdomo ( Pp. 4-26)}

Lo expresado, realza la importancia de consolidar la formación en vivencias reales de lo que acontece en la comunidad, para que practique la enseñanza de acuerdo a la reflexión sobre el acontecer, el hacer y el ser, sobre lo importante del impacto transformador de relacionar el contexto con las actitudes y valores que se fomentan. Entonces, se debe enseñar en y desde la mirada del otro, por lo que sólo desde la reflexión, la meditación y el ejercicio de la autocrítica de lo que se está haciendo en beneficio del otro es, que realmente se aprende a enseñar. Visto así, se esbozará a continuación los fundamentos de este nuevo saber emergido de la reflexión teórica:

\section{Dimensión Epistemológica}

Al referenciar los fundamentos epistémicos que encierran el hacer del servicio comunitario de los docentes en formación inicial de educación especial, se considera la ceguera paradigmática, quien Morín (2001), la denomina fuentes de error porque las personas tienden a pensar, conocer y actuar conforme a los mitos, creencias y prejuicios ante situaciones desconocidas y nuevas. Estos atributos por lo general son producto de las emociones que preparan al ser para la acción, las cuales se presentan como la incertidumbre y el miedo derivados de las percepciones intrínsecas cargadas de emotividad por la angustia de la nueva vivencia.

La ceguera paradigmática presente en la persona tiene que ver según Freud (1919), con las antiguas creencias que viven en el inconsciente, por lo que dominan en el ser ya que son producto de las experiencias vividas en el ámbito familiar y social. Asó, cuando sucede algo o se vive susceptible de despertar aquellas viejas convicciones dormidas, es cuando se experimenta emociones de incertidumbre y miedo. Por tal motivo, desde la mirada de la complejidad Morín (ob.cit) invita a superar lo anterior desde la ecología de la acción que comprende cuatro principios:

El bucle riesgo precaución, para accionar dentro de una nueva experiencia primeramente la persona trata de entrelazar el riesgo y la precaución con la finalidad de superar la angustia que invade al ser, en la vivencia de la experiencia sistematizada ello se logra, mediante los sentimientos de motivación y emoción del yo para superar la 
estigmatización de los juicios, creencias y prejuicios que invaden al estudiante universitario, al ejecutar sus prácticas profesionales diferentes de lo que se le ha enseñado.

El bucle fines medios, el autor en cuestión reafirma que los fines y los medios interretro-actúan, es inevitable que los medios innobles al servicio de fines nobles alteren y terminen por sustituirlos. La acción social, la define el fin en sí mismo a través del aprendizaje en servicio, que permite desvanecer de una u otra manera, la ceguera paradigmática de una acción comunitaria llena de angustia, incertidumbre y el miedo por lo desconocido. Por lo que la emoción y motivación, arraigada por la solidaridad, responsabilidad y corresponsabilidad, es la pureza de los medios que conducen al fin deseado en la ejecución.

Bucle acción contexto, por lo general toda acción escapa de la voluntad, cuando entra en juego las inter-retroacciones del medio donde se interviene, pero en el accionar comunitario la voluntad es el valor que permite la superación de los mitos, creencias y prejuicios, ya que, el primer contacto con la realidad acontecida en una comunidad permite hacer la pausa para mirar en el contexto no un medio sino, un fin en sí mismo fuente de enseñanza sobre el ser, el hacer, el acontecer y sobre el impacto transformador que ello vislumbra.

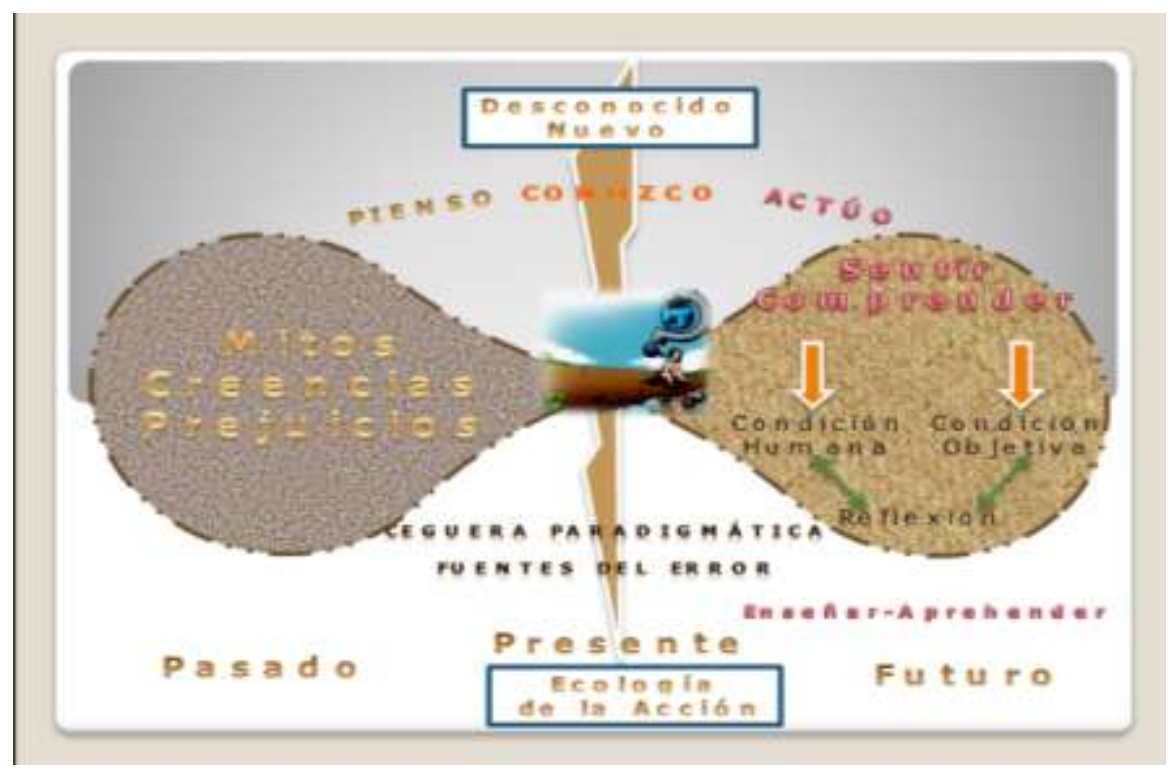

Gráfico 1. Dimensión Epistemológica de Hacer del Servicio Comunitario en los Estudiantes de Educación Especial. Autor. 


\section{Ser y hacer del servicio comunitario: aproximación desde el contexto formación inicial en Educación Especial \\ Yarines Perdomo ( Pp. 4-26)}

En el gráfico anterior, se reafirma que, solo desde el sentir del actor protagonista de la ecología de la acción, es que se promueve el cambio paradigmático de las cegueras intrínsecas presentes en la persona, evidenciado según Morín, en la importancia de enseñar en la comprensión. Así el autor señalado, afirma que existen dos tipos de comprensión, la comprensión intelectual u objetiva y la comprensión humana subjetiva, ambas requieren entrelazarse para superar el Aprendizaje de la explicación, es decir emoción y razón se conjugan para la simpatía, generosidad, empatía, de identificación y proyección del ser en el hacer.

Del mismo modo, el conocimiento se construye y se emancipa a partir de los proyectos ejecutados en los espacios comunitarios de atención no convencional, mediante la relación del saber, que se produce por la naturaleza, característica y resultado de la acción; considerando el trabajo colaborativo para el diagnóstico, planificación de las estrategias de acción, ejecución y evaluación del proceso llevado a cabo. La reflexión de la acción mediante la realización de actividades construidas con la comunidad desde sus necesidades reales, permite el surgimiento del nuevo conocimiento para responder a los requerimientos e intereses de la realidad acontecida.

\section{Dimensión Ontológica}

La fundamentación ontológica refiere a las categorías amplias que sustentan las bases de la dimensión epistemológica, en atención a la concepción del ser. La sociedad y su realidad se conjugan en el interés cognitivo, crítico, amoroso, complejo y emancipador para generar una visión del hombre como ser social unidual que, visto desde la Psicología Positiva, trata de comprender las fuentes los procesos y mecanismos que conducen al hombre a éxitos deseables.

El interior y sentido de la vida, compuesto por las metas y virtudes de un ser unidual que media entre las circunstancias externas y la calidad de la experiencia. El cómo interpretar lo que sucede es determinante para su felicidad (Seligman, ob. cit). Esta premisa, destaca promover las fortalezas personales del estudiante universitario en educación especial; la cual se alcanza al potenciar la gratificación por lo que hace; siendo

Revista EDUCARE, Volumen 18, Número 3, Septiembre - Diciembre 2014. ISSN: 2244-7296 Página 13 
Ser y hacer del servicio comunitario: aproximación desde el contexto formación inicial en Educación Especial

Yarines Perdomo ( Pp. 4-26)

el sentido más amplio de la teorización del nuevo conocimiento que, surge desde la vivencia significativa de los estudiantes prestadores del servicio comunitario.

Cuando la persona se compromete con su hacer, utiliza sus fortalezas personales, emociones y aptitudes para afrontar e interpretar los acontecimientos de la realidad, y así lograr la meta trazada mediante la gratificación. El autor antes citado, conceptualiza la gratificación como el esfuerzo intencional de la persona que despliega sus fortalezas y virtudes, derivadas de las actividades que le gusta realizar. La significación por lo que se hace, forja el trascender de la vida del hombre; es la autorrealización expuesta por Roger (ob. cit) en el enfoque humanista.

De allí, que los sentimientos se presentan como la voluntad que motiva la acción, la cual permite determinar la meta a alcanzar. Disponer de una motivación profunda en la significancia del hacer, conlleva a la realización intrínseca, bienestar y transformación de la realidad vivida.

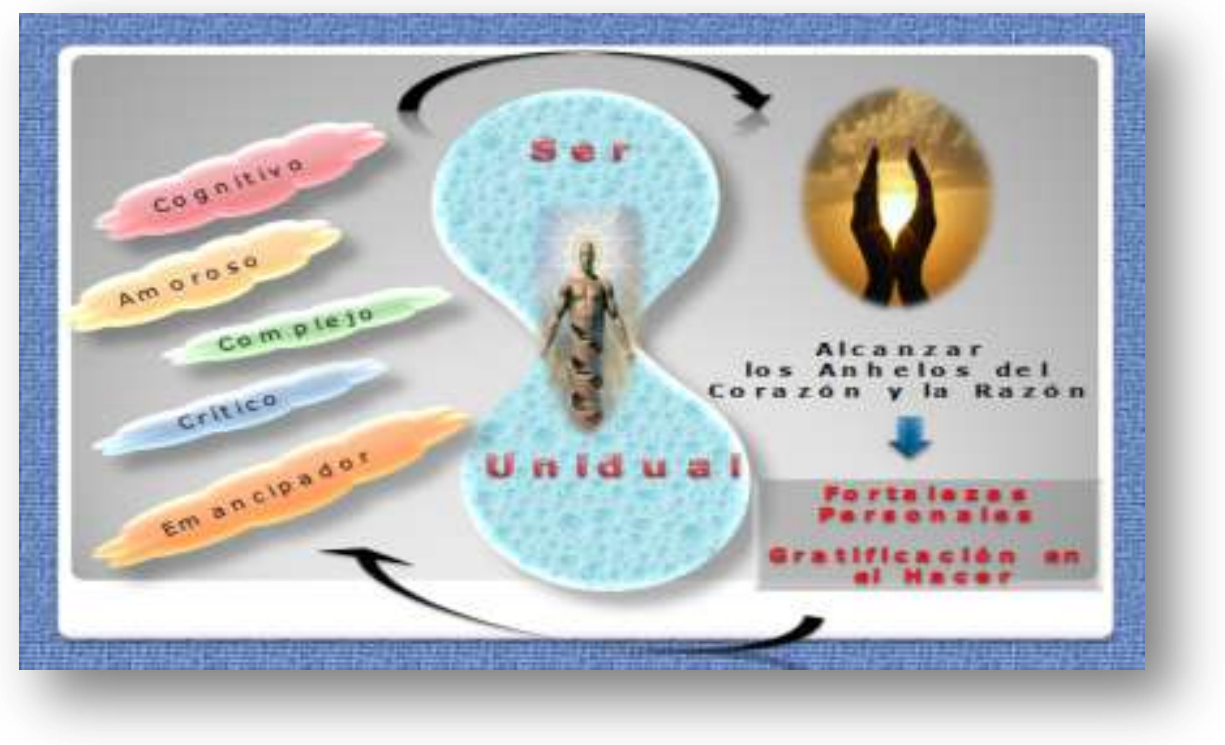

Gráfico 2. Dimensión Ontológica de Hacer del Servicio Comunitario en los
estudiantes de Educación Especial. Autor.

Lo expuesto anteriormente en el gráfico anterior, implica colocar las fortalezas personales al servicio del conocimiento, la comunidad, la familia. Formarse para ejercer una profesión que, hace sentir el servicio prestado para los demás, proporciona una

Revista EDUCARE, Volumen 18, Número 3, Septiembre - Diciembre 2014. ISSN: 2244-7296 Página 14 


\section{Ser y hacer del servicio comunitario: aproximación desde el contexto formación inicial en Educación Especial \\ Yarines Perdomo ( Pp. 4-26)}

sensación permanente de bienestar, una felicidad de fondo. En el sentido más amplio, la premisa anterior rescata el ser unidual, integrado de saberes, de un sentido estético y espiritual que, le hacen accionar dentro del contexto para trascender desde su potencial creativo e innovador.

En este orden de ideas, se estima entonces considerar la visión del docente en formación inicial en educación especial durante la práctica del servicio comunitario. Una práctica centrada convertir sus criterios de acción, entrelazando el interés cognitivo, emocional y crítico emancipador; para develar transformaciones profundas dentro de su accionar, con una preocupación diacrónica propugnada por un dinamismo de la realidad.

\section{Dimensión Axiológica}

La fundamentación axiológica de esta aproximación teórica, se conjuga con las fortalezas personales expuestas por Peterson y Seligman (2009), quienes las definen, como estilos moralmente valorables de pensar, sentir y actuar que contribuyen a una vida plena; ello hace explícita las interrogantes ¿quién soy?, ¿qué realizo? y ¿cómo lo realizo?, dichas preguntas fomentan la introspección y promueve el perfil ético que debe poseer el estudiante comunitario en educación especial, mediante el reconocimiento y puesta en práctica de las virtudes operativas determinadas por las fortalezas personales, las cuales son clasificadas por los autores en cuestión como:

Sabiduría y conocimiento, fortalezas cognitivas que implican el saber y conocer, en ella se encuentran la creatividad, curiosidad, apertura por el pensar críticamente, amor por el aprendizaje y la perspectiva para comprender el mundo y para ayudar a comprenderlo a los demás.

Coraje, fortaleza emocional que implica el ejercicio de la voluntad para la consecución de las metas, incluye los valores de valentía, perseverancia, integridad y vitalidad.

Humanidad, fortalezas interpersonales que implica ofrecer amistad y cariño a los demás, en ella se realza el valor del amor, amabilidad, inteligencia emocional social, ser consciente de las emociones y motivaciones tanto del ser como de los otros.

Revista EDUCARE, Volumen 18, Número 3, Septiembre - Diciembre 2014. ISSN: 2244-7296 Página 15 
Justicia, fortalezas cívicas que conllevan a convivir confortablemente, implica el trabajo colaborativo, sentido de justicia y liderazgo.

Moderación, fortalezas que promueven la capacidad de perdonar, la modestia, humildad, prudencia y autocontrol para regular los propios sentimientos y acciones.

Trascendencia, fortalezas que realzan la significación por lo que se hace, implican la apreciación por la belleza y la excelencia, gratitud, sentido del humor y espiritualidad, pensar que existe un propósito o un significado universal en las cosas que ocurren en el mundo y en la propia existencia.

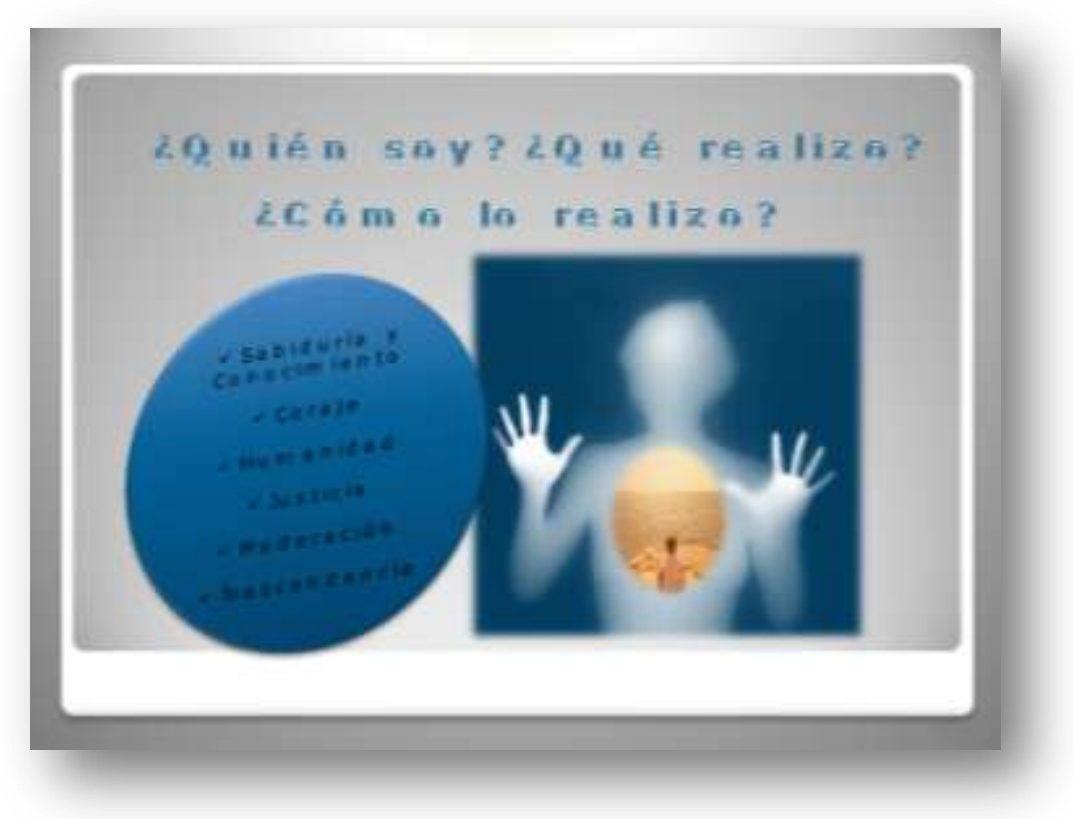

Gráfico 3. Dimensión Axiológica de Hacer del Servicio Comunitario en los estudiantes de Educación Especial. Autor.

Así, en el gráfico anterior todas estas fortalezas de algún modo se vislumbran en el accionar de los docentes en formación inicial prestadores del servicio comunitario; y realzan que la educación del docente comunitario en educación especial, requiere articular su perfil ético para transformar los cambios de la sociedad. Ello, es redescubrirse dentro de un enseñar y aprender, dialógico significativo que contribuya, expanda y consolide el conocer, para abrir un abanico de posibilidades, que trascienda las fronteras y obstáculos de 


\section{Ser y hacer del servicio comunitario: aproximación desde el contexto formación inicial en Educación Especial \\ Yarines Perdomo ( Pp. 4-26)}

accesibilidad, discriminación y disponibilidad, que se escucha profundamente desde las voces de las personas con discapacidad.

En tal sentido, se instaura una concepción ética, crítica y reflexiva como comprensión y transformación de la educación en esta era planetaria, donde hoy son responsables los formadores de formadores y le atañe a quienes visualizan una nueva educación especial que, sea del alcance para todos desde un cambio conceptual y práctico. Con la finalidad, de promover en el futuro docente las virtudes y valores antes mencionadas.

\section{Dimensión Gnoseológica}

Los fundamentos gnoseológicos, según Sánchez (2001), tienen que ver como la manera de concebir el objeto y de relacionarlo con el sujeto en el proceso cognoscitivo, así en esta construcción teórica, el conocimiento fue generado de la propia experiencia emocional fruto del sentido y del entendimiento que partiendo de una realidad particular permitió la abstracción para la fundamentación de las concepciones presentes en la realidad. Dichas concepciones, se basaron en un proceso de indagación, acción y reflexión en la transformación de ciertos aspectos sociales para emancipar a las personas participantes de este proceso.

En consecuencia, el proceso formativo del docente en formación inicial de educación especial, se concibe como un proceso simbólico de cambio y transformación liderados y direccionados por aquellos que se han trazado la meta de contribuir de manera inmediata en la inclusión social de las personas con compromiso educativo y potencialidades. El futuro docente, como promotor social se debe a un presente que, proyecta y requiere la realización de prácticas educativas significativas transformadoras de las necesidades reales de la comunidad en general; un docente cuyo ideal es, alcanzar la gratificación de lo que se hace mediante el compromiso significativo y auténtico con su nivel profesional.

Para lograr lo anterior, el docente en formación amerita desarrollar habilidades y destrezas positivas que según Goleman (ob. cit), promueven el autodominio, la persistencia, y la capacidad para motivarse para no ser afectado por los impulsos pocos favorables del medio donde se desenvuelve, conocidos estos como las cegueras paradigmáticas del 


\section{Ser y hacer del servicio comunitario: aproximación desde el contexto formación inicial en Educación Especial \\ Yarines Perdomo ( Pp. 4-26)}

prejuicio, mitos y creencias que acontecen antes o durante la vivencia de la experiencia. Así, se enfatiza que la universidad forme a los futuros docentes en educación especial, mediante la consolidación y desarrollo emocional para la participación comunitaria activa y positiva.

La acción docente que toma en cuenta estos postulados, crea las condiciones que apoyan al estudiante universitario en su formación plena, para potenciar actitudes positivas de conciencia y bienestar con la finalidad de promover el desarrollo personal que desde las ideas de Maturana (ob. cit), nos es más que enseñar a vivir en el autorrespeto y respeto por el otro, el transformar las necesidades en habilidades y potencialidades para alcanzar la adaptación y transformación de la esfera comunitaria donde el estudiante vive y convive. Este proceso formativo cuando es totalmente emocional y positivo para el futuro docente en formación permite que, fluya el control sobre la experiencia accionada sobre la base de los rasgos característicos de las fortalezas personales del ser; entonces el camino a seguir según Seligman (ob. cit), es primeramente tener clara la meta a alcanzar; involucrarse, sentirse inmerso y comprometido con la acción, disfrutar del hacer prestando atención a los obstáculos que se presentan para que con la voluntad, empatía y el optimismo puedan superarse.

De allí, cobra relevancia el formar holísticamente al futuro docente en educación especial, que desde la voz de Gallegos (2001), es un conducto de transformación de la conciencia, que permite despertar el conocimiento de la naturaleza espiritual en sí mismo y en el otro.

La idea anterior, realza la finalidad en el proceso formativo del futuro docente, que se centra en lograr_su bienestar, nutriendo su inteligencia racional, emocional y espiritual, para lograr el equilibrio pleno en el desarrollo de una práctica profesional gratificante y feliz.

Es así como se alcanza el aprendizaje auténtico propuesto por Villarini (ob. cit), el ser ama y anhela aprender, entonces el ser y el conocer se entrelazan, conjugan en su esencia para ser feliz a pesar de la circunstancia, sentir y manifestar amor, vivir para servir, ser independiente y autónomo, encontrar la significación de lo que se hace, resolver los 
Ser y hacer del servicio comunitario: aproximación desde el contexto formación inicial en Educación Especial

Yarines Perdomo ( Pp. 4-26)

problemas con la unicidad de valores y virtudes personales y sobre todo aprender a ser, vislumbrando y sembrando la paz.

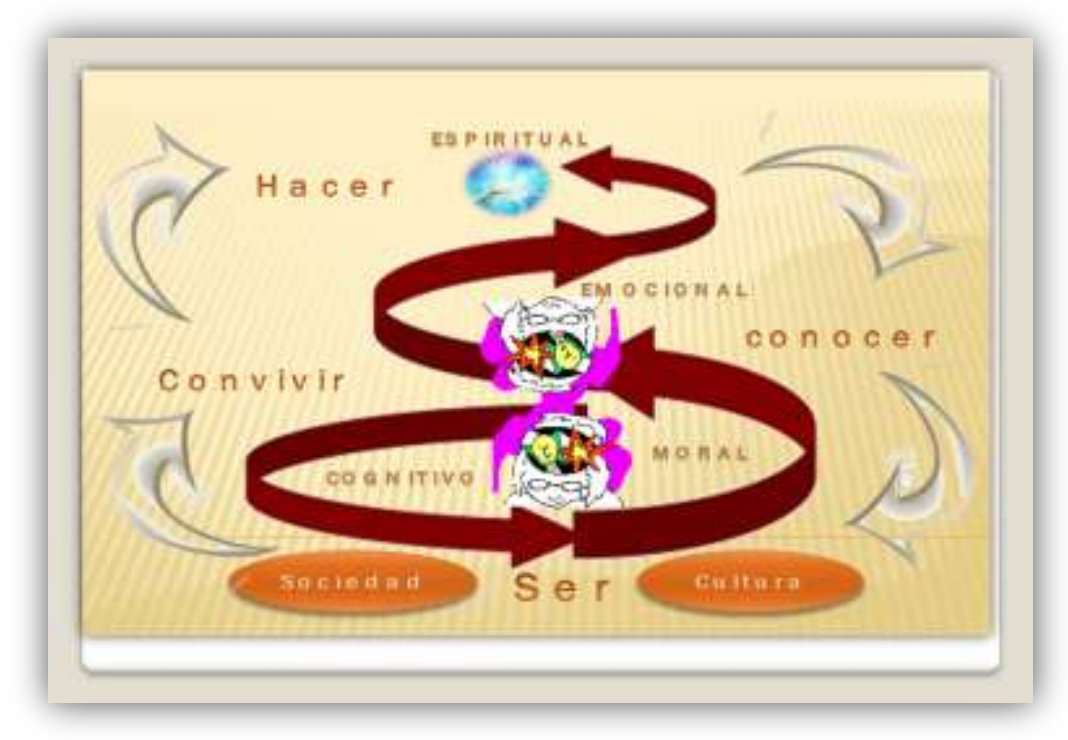

\section{Gráfico 4. Dinámica Gnoseológica de Hacer del Servicio Comunitario en los} Estudiantes de Educación Especial. Autor.

En el diagrama en referencia se aborda la formación plena, holística y unidual de lo que pretende realzar esta indagación desde la gnoseología, dicha educación se profundiza desde una espiral dinámica que realza la capacidad potencial, virtuosa, emocional y espiritual necesaria para ejercer una praxis emancipadora comprometida y gratificante. Buscar en la interioridad del ser humano para formarlo de acuerdo a los requerimientos de la sociedad y la cultura es lo que promueve la unidad de la percepción del sentir de los otros, es aprender auténticamente en y para transformar realidades que a la luz de la era planetaria pudiesen ser inalcanzable; sólo se humaniza al ser humano cuando el formador tiene una conciencia espiritual y amorosa, vínculo que edifica la construcción de los niveles más altos para lograr la accesibilidad de aquellos excluidos por una sociedad que necesita fomentar la cultura de paz, justicia y felicidad.

\section{Dimensión Pedagógica}

Esbozar los fundamentos pedagógicos de esta aproximación teórica invitan a 


\section{Ser y hacer del servicio comunitario: aproximación desde el contexto formación inicial en Educación Especial \\ Yarines Perdomo ( Pp. 4-26)}

profundiza a partir la hermenéutica, desde la concepción intrínseca del hombre para su

proceso formativo. Éste es en un haz de experiencias, y cada nueva experiencia nace sobre el trasfondo de las experiencias para reinterpretarlas.

Así, al mediar el proceso de formación inicial del docente en educación especial en el hacer no convencional, arriba a enseñar desde la historicidad concreta de las realidades sociales del contexto en evolución hacia el mañana, fundamentada en el sentir y en el pensar, que rehace la alianza entre lo racional y lo intuitivo. Lo anterior genera en el docente en formación inicial, el desarrollo y consolidación de las competencias necesarias para afrontar la práctica profesional, como un medio en sí mismo para educar en la reflexión, autoreflexión, la crítica, la autocrítica, la autoformación y la trasformación.

Es por ello, que se propone una formación comprensiva que utilice la dialogicidad para conocer las necesidades del otro, de la sociedad, de la comunidad y sus miembros, para argumentar las propuestas y sustentar las decisiones de manera reflexiva, creativa y con mayor consistencia moral en su quehacer cotidiano.

En este sentido, cobra relevancia las competencias sociales a vigorizar y desarrollar en el proceso formativo, definidas como virtudes y fortalezas personales que integran el sentir y el pensar para la reflexión y autoreflexión del ser en el hacer con la finalidad de alcanzar el desarrollo personal y profesional para actuaciones sociales que se adecuen y transformen un contexto específico.

Así estas competencias las podemos clasificar en: a) Competencias Personales del Sentir, b) Competencias Personales del Hacer y c) Competencias Personales de Acción Comunitaria. Las competencias personales del sentir, se definen como aquellas habilidades intrínsecas que conllevan al alcance de la felicidad y autorrealización mediante el fortalecimiento de las virtudes de sabiduría y conocimiento, coraje, justicia, moderación, humanidad y trascendencia. Las competencias personales de acción conllevan a vincular las fortalezas personales, las emociones y sentimientos con el pensar, que a través de la dialogicidad y significatividad por lo que se hace se logra el aprendizaje auténtico que permite alcanzar los niveles más altos de gratificación; en ella se vislumbra la creatividad, curiosidad, apertura mental, amor por el aprendizaje, perspectiva, perseverancia, ciudadanía y autocontrol.

Revista EDUCARE, Volumen 18, Número 3, Septiembre - Diciembre 2014. ISSN: 2244-7296 Página 20 
Ser y hacer del servicio comunitario: aproximación desde el contexto formación inicial en Educación Especial

Yarines Perdomo ( Pp. 4-26)

Por último, la competencia personal de acción comunitaria, son las que promueven el desempeño y puesta en práctica de las demás competencias para la transformación de las realidades acontecidas dentro de un contexto específico, implican la coordinación, planificación y trabajo colaborativo para abordar significativamente las necesidades del mismo.

Entonces, se deduce que la atención plena y holística del desarrollo y fortalecimiento de estas competencias durante el proceso formativo del futuro docente, permitirán potenciar actitudes de control y autoconciencia emocional, para el alcanzar las fortalezas personales que transformen los rasgos positivos de su personalidad en el hacer.

Fundamentada esta aproximación teórica paradigmática es posible interrogarse, finalmente, ¿cuál debe ser la formación académica del docente en formación inicial en Educación Especial para la labor social del servicio comunitario? A la luz del hacer universitario, debe concebirse como una función inherente a lo académico, que involucra la investigación y extensión, con la finalidad de promover en el estudiante las potencialidades, habilidades y actitudes tendientes al bien común y al bienestar social.

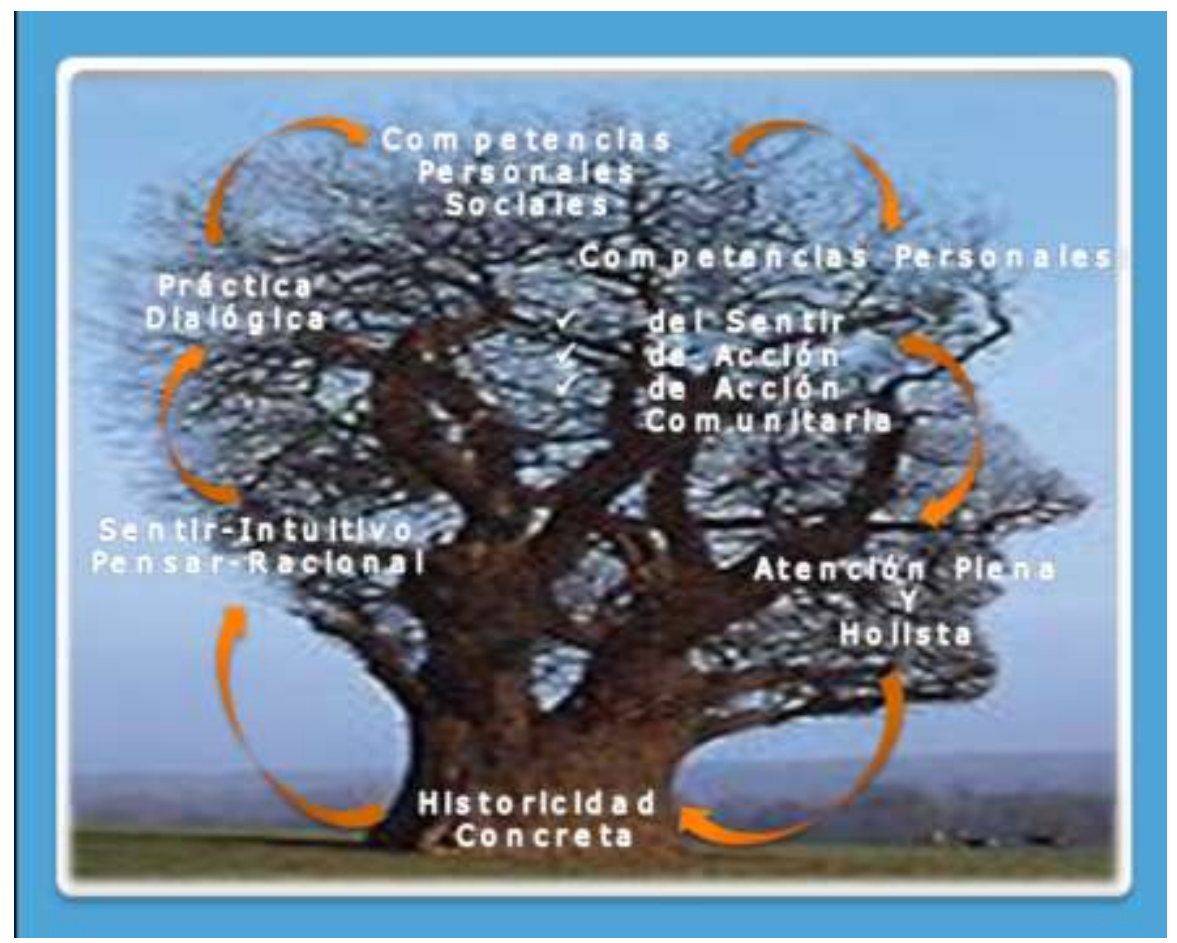

Gráfico 5. Dimensión Pedagógica de Hacer del Servicio Comunitario en los Estudiantes de Educación Especial. Autor.

Revista EDUCARE, Volumen 18, Número 3, Septiembre - Diciembre 2014. ISSN: 2244-7296 Página 21 


\section{Ser y hacer del servicio comunitario: aproximación desde el contexto formación inicial en Educación Especial \\ Yarines Perdomo ( Pp. 4-26)}

En tal sentido, y según el gráfico expuesto, el docente en formación inicial de educación especial se concibe como un ser protagónico, que ejecuta acciones comunitarias de inclusión social para las personas con discapacidad, su familia y la comunidad, y que mediante el uso de estrategias no convencionales y la regla acción-reflexión-acción, logra promover los saberes y haceres a través de experiencias significativas y dialógicas dentro del contexto social donde acciona, para así alcanzar la atención holística y plena de las personas que atiende.

\section{REFLEXIONES FINALES}

Las creencias, prejuicios y mitos que tienen los docentes en formación inicial dentro del contexto universitario, dependen generalmente de la practicidad del docente que los forma y, son según Prieto (ob.cit), el eje vertebrador de la calidad docente. Es así como la creencia pedagógica que la atención no convencional se presenta como, una alternativa de inclusión, adaptación y acceso a la educación por aquellos que están excluidos del sistema educativo formal, es una fuente primordial para la generación de expectativas positivas en cuanto al accionar del estudiante en su accionar comunitario de educación especial.

La perspectiva del ser sobre el hacer, depende primordialmente de las fortalezas personales y de las habilidades pedagógicas que se tengan para llevar a cabo una práctica reflexiva significativa, la promoción del amor por lo que se hace es la raíz que sustenta la eficacia y autoeficacia altruista del docente en formación inicial en su práctica comunitaria. Así, la eficacia se define como la capacidad de alcanzar una meta mediante la realización de un conjunto de acciones; la eficacia en el docente en formación inicial de educación especial, es el conjunto de acciones amorosas, significativas y dialógicas que permiten la atención plena y holística de la persona con discapacidad en su familia, comunidad y la sociedad de la cual forma parte.

Cabe destacar, que la eficacia de su accionar dependerá de la convicción de qué se puede y se anhela lograr y es allí donde la autoeficacia ejerce el poder cognitivo para generar a través de las fortalezas personales, emociones y sentimientos la satisfacción y

Revista EDUCARE, Volumen 18, Número 3, Septiembre - Diciembre 2014. ISSN: 2244-7296 Página 22 


\section{Ser y hacer del servicio comunitario: aproximación desde el contexto formación inicial en Educación Especial \\ Yarines Perdomo ( Pp. 4-26)}

felicidad por lo que se hace. Entonces, la autoeficacia, es la percepción cognitiva y emocional de las fortalezas personales, emociones y habilidades para alcanzar el éxito, es el impulso emotivo y comprometido del ser sobre su hacer. El altruismo, por su parte hace referencia a la búsqueda del bienestar del otro, la fortaleza altruista del estudiante universitario de educación especial es la virtud preponderante en la vocación de servir en y para las personas con compromiso específico y potencialidades, la familia y su comunidad.

Ahora bien, la eficacia y autoeficacia altruista del docente en formación inicial se entrelaza con el ser y hacer para generar la toma de decisiones asertivas en cuanto a la atención plena de la población a su cargo, una atención efectiva, sentida y valorada por quien la lleva a cabo y por quien se beneficia de ella; una acción caracterizada por el compromiso, solidaridad, responsabilidad, voluntad, motivación y satisfacción por lo que se hace. Al respecto, Aristóteles expresaba que la docencia es una virtud porque es bueno enseñar y por lo mismo deseable y es bueno enseñar porque sin educación los hombres no pueden alcanzar sus metas e ideales de vida buena; sin una formación y práctica educativa altruista es imposible desplegar la capacidad de desarrollar en el ser la autonomía de pensar críticamente.

Lo expresado se adecua al deseo de enseñar, conociendo y realzando el deseo del otro, la aspiración de alcanzar un valor, una virtud y un bien que se puede reconocer en la práctica docente en sí misma, que no es más que la pretensión de relacionar el pensar, el sentir y el hacer con la realización plena de quien se educa. La esperanza de la acción pedagógica comunitaria como bien eficaz y altruista hila estudiantes libres e iguales, reconocidos en el convivir consigo mismo y con los otros respetando y reconociendo sus diferencias, aprendiendo de ellas para erigir una sociedad justa basada en valores de igualdad, libertad, respeto, solidaridad y el diálogo.

Esta concepción, implica tanto en los profesores y docentes en formación inicial en el ámbito de la educación especial afrontar nuevos y complejos retos frente a los profundos cambios que deben enfrentarse con sentimiento de amor, creencia y significación por lo que se hace, siendo ello el determinismo recíproco del que hace mención Bandura (1997), 
que no es más que conjugar y equilibrar los factores personales internos con los factores externos y el comportamiento.

En otras palabras, es relacionar la eficacia y autoeficacia con la fortaleza altruista para lograr la reflexión y significación de los haceres, desde la formación inicial del docente, que lleve a replantearse y reflexionar sobre las incertidumbres del futuro, en las responsabilidades y retos del hoy inmediato, por lo que debe comprometerse con la naturaleza del accionar abriendo las puertas del encuentro con el pensamiento del otro y de los otros, eligiendo en cada situación lo mejor y así alcanzar la felicidad en su hacer.

Las experiencias exitosas del hoy, son las que estimulan los cambios virtuosos y emancipadores del mañana; la tarea no es sólo enseñar, no es hacer lo posible, es crear lo que se cree imposible.

\section{REFERENCIAS}

Bandura, A. (1997). Self-efficacy: The Exercise of Control. New York: WH.

Constitución de la República Bolivariana de Venezuela (1999). Gaceta Oficial 38.680 del 30/12/1999. Caracas - Venezuela.

Freud, S. (1919). Lo siniestro. Obras Completas. Disponible en http://www.librosgratisweb.com/html/freud-sigmund/lsiniestro/index.htm. Consultado 15-04-2011.

Gallegos, R. (2001). Educación holísta. Pedagogía del amor universal. Guadalajara: Fundación Internacional para la Educación Holísta.

Giménez, R. (2007). Estimulación de la Inteligencia Emocional para Fortalecer la Praxis Pedagógica en Docentes de la UPEL_IPB: Teorización. Barquisimeto: Universidad Pedagógica Experimental Libertador. Programa Interinstitucional de Doctorado en Educación UCLA UNEXPO UPEL.

Goleman, D. (1997). La Inteligencia Emocional. Buenos Aires: FURESA.

Ley de Servicio Comunitario del Estudiante de Educación Superior (2005). Gaceta Oficial No 38.272 de fecha 14 de septiembre de 2005. República Bolivariana de Venezuela.

Ley Orgánica de Educación (2009). Gaceta oficial de la República Bolivariana de Venezuela, 2635. (Extraordinaria), julio 28,2009.

Revista EDUCARE, Volumen 18, Número 3, Septiembre - Diciembre 2014. ISSN: 2244-7296 Página 24 
Ser y hacer del servicio comunitario: aproximación desde el contexto formación inicial en Educación Especial

Yarines Perdomo ( Pp. 4-26)

Martínez, M. (1997). El Paradigma Emergente. México: Trillas.

Maturana, H. (2011). Formación Humana y Capacitación. Chile: Dolmen.

Maza, D. (2001). La Universidad que Necesitamos. El Nacional (miércoles 25 de Abril, p.A-8).

Morín, E. (2001). Los siete saberes necesarios para la Educación del futuro. Colombia: Mesa redonda magisterio.

Organización de Estados Iberoamericanos para la Educación, la Ciencia y la Cultura (OEI) (2010). 2021 Metas Educativas la Educación que Queremos para la Generación de los Bicentenarios. España: Cudipal

Organización de las Naciones Unidas, para la Educación, la Ciencia y la Cultura. (UNESCO) (2008). Conferencia Internacional de Educación. La educación inclusiva el camino hacia el futuro. Ginebra: Oficina Internacional de Educación.

Organización de las Naciones Unidas, para la Educación, la Ciencia y la Cultura. (UNESCO) (2009). Conferencia Mundial sobre la Educación Superior: La Nueva Dinámica de la Educación Superior y la búsqueda del Cambio Social y el Desarrollo. Paris: WCHDCMES.

Peña, M. (2006). La Cultura Emocional en la Universidad. Barquisimeto: Universidad Pedagógica Experimental Libertador, Instituto Luis Beltrán Prieto Figueroa. Tesis Doctoral.

Pérez, A. (2007). Necesidad de una nueva cultura educativa. Extractos de la ponencia ofrecida en CERPE el 18 de abril de 2007.

Pérez, Z. (2009). La Práctica Docente en la Modalidad No Convencional: UPEL-IPC. Venezuela: Red de Investigadores en Educación de América y el Caribe (RIEAC). Disponible en http://www.rieac.com/articulos.html. Consultado el 17-04-2011.

Peterson, Ch. y Seligman, M. (2009). El estudio Científico de las fortalezas humanas. Madrid: Alianza.

Prieto, F (1978). Principios Generales de la Educación. Caracas: Monte Ávila.

Rogers, C. (1978). .Libertad y Creatividad en la Educación. Barcelona: Paidos.

Sánchez, A. (2001). La formación del docente para la educación venezolana. Caracas. Salecina, S.A

Seligman, M. (2005). La auténtica felicidad (M.Diago \& A. Debrito, Trads.). Colombia: Imprelibros. (Trabajo original publicado en 2002).

Revista EDUCARE, Volumen 18, Número 3, Septiembre - Diciembre 2014. ISSN: 2244-7296 Página 25 
Ser y hacer del servicio comunitario: aproximación desde el contexto formación inicial en Educación Especial

Yarines Perdomo ( Pp. 4-26)

Universidad Pedagógica Experimental Libertador (2011). Documento Base del Currículo UPEL 2011. Caracas: UPEL.

Villarini, A. (2006). Calidad Educativa desde una perspectiva humanística, crítica y emancipadora. Puerto Rico: Crecemos.

Revista EDUCARE, Volumen 18, Número 3, Septiembre - Diciembre 2014. ISSN: 2244-7296 Página 26 